\title{
AUTOCONCEITO, AUTO-EFICÁCIA PROFISSIONAL E COMPORTAMENTO EXPLORATÓRIO EM UNIVERSITÁRIOS CONCLUINTES
}

\author{
Marucia Patta Bardagi * \\ Raquel de Melo Boff **
}

Recebido em: 21 de janeiro de 2010

Aprovado em: 30 de janeiro de 2010

\begin{abstract}
*Graduação pela Universidade Federal do Rio Grande do Sul, Mestrado e Doutorado e Pós Doutoranda na área de Desenvolvimento de Carreira pela Universidade Federal do Rio Grande do Sul. Professora da Universidade Luterana do Brasil ULBRA - Santa Maria.E-mail: marucia.bardagi@gmail.com.

**Formada em Psicologia pela Universidade de Caxias do Sul - 2006 e Pós Graduação em Psicoterapia cognitivo comportamental pela Universidade Federal do Rio Grande do Sul - 2009. Email: rmboff@hotmail.com.
\end{abstract}

Resumo: Este estudo avaliou os níveis de clareza de autoconceito, auto-eficácia e comportamento exploratório em universitários em fase de conclusão de curso. Investigou-se 231 formandos de uma Universidade privada do interior do Rio Grande do Sul, homens e mulheres com idades entre $18 \mathrm{e}$ 30 anos. Resultados apontam que encontrar um emprego na área é o plano da maioria dos jovens após a formatura, embora um percentual relevante $(52,8 \%)$ já esteja colocado no mercado de trabalho. Houve correlação positiva entre comportamento exploratório, clareza de autoconceito e auto-eficácia, e os dados revelam que estudantes dispostos a engajar-se em atividades acadêmicas ou extracurriculares têm a tendência em ter projetos mais estruturados e expectativas mais realistas diante do mercado de trabalho. Estes resultados indicam que os universitários necessitam de um acompanhamento neste processo de transição, especialmente no âmbito da elaboração de metas e projetos profissionais.

Palavras-chave: Autoconceito. Auto-eficácia. Comportamento exploratório.

\section{SELF-CONCEPT, PROFESSIONAL SELF-EFFECTIVENESS AND EXPLORATORY BEHAVIOR IN UNIVERSITY SENIORS}

\begin{abstract}
This study evaluated the levels of self-concept, self-effectiveness and exploratory behavior in senior university students. 231 students of a private University in the state of Rio Grande do Sul, men and women with ages between 18 and 30 years, were studied. Results show that finding a job in the field of their major is the plan of the majority of the students after graduation, even though a great percentage $(52.8 \%$ ) is already placed in the work market. Positive correlations were found between exploratory behavior, self-concept and self-effectiveness, and students who engage in academic or extracurricular activities tend to have more structured projects and more realistic expectations towards the work market. These results indicate that students need support in this transitional period, especially concerning the definition of career goals and projects.
\end{abstract}

Key Words: Self-concept. Self-effectiveness. Exploratory behavior.

\section{INTRODUÇÃO}

A conclusão de uma graduação é o momento no qual o jovem adulto entra no estágio do estabelecimento profissional buscando firmar um novo papel: o de trabalhador. Os poucos estudos no Brasil envolvendo este momento de 
transição revelam que a maioria dos jovens tem o desejo de atuar na profissão para a qual se qualificou. Diante disso, se deparam com inúmeras variáveis que podem influenciar no planejamento profissional futuro. Dentre estas, há variáveis não controláveis, como o número de oferta de trabalho na profissão escolhida, a economia regional, a competitividade do mercado, etc. Apesar disso, há fatores que influenciam este momento e estão relacionados à maneira como o formando se comportou durante a graduação, bem como sua percepção acerca deste novo papel de trabalhador. Nesse sentido, identificar aspectos como a clareza de autoconceito, a auto-eficácia percebida, o nível de comportamento exploratório e a satisfação com o curso podem auxiliar na compreensão de como são construídas as expectativas futuras dos formandos.

Para Super (1963a), teórico importante do desenvolvimento vocacional e de carreira, o autoconceito significa a avaliação pessoal que o individuo faz de suas aptidões, interesses, valores e escolhas, bem como da forma com que estes aspectos organizam-se em seus temas de vida. $\mathrm{O}$ autoconceito refere-se ao quanto as crenças relativas a si mesmo (ou seja, aos atributos pessoais percebidos) são claramente definidos, consistentes e estáveis no tempo (CAMPBELL; TRAPNELL; HAINE; KATZ; HAINE, 1996). O autoconceito vocacional, especificamente, seria um dos componentes do sistema de autoconceito e define-se pela constelação de atributos do eu que o indivíduo considera vocacionalmente relevantes sejam ou não estes referidos como preferências vocacionais.

As expectativas em relação ao futuro profissional podem também estar ligadas, dentre outros fatores, às crenças de auto-eficácia (BZUNECK, 1996; TEIXEIRA 2002; TEIXEIRA; GOMES, 2005). Este conceito é um destaque na teoria social cognitiva de Bandura (1992) e refere-se ao julgamento das pessoas sobre suas capacidades para organizar e executar cursos de ação necessários para alcançar certos tipos de desempenho, ou seja, são percepções que os indivíduos têm sobre suas próprias capacidades, a base para a motivação humana, o bem estar e as realizações profissionais. Para o autor, pessoas com uma forte percepção de auto-eficácia poderiam experimentar menos estresse em situações que demandam mais esforço pessoal. Desta forma, estudantes universitários com altos escores de auto-eficácia poderiam encontrar a motivação e a persistência necessárias para alcançar um determinado objetivo, através de dois processos: os motivacionais, projetados pelo esforço e perseverança, manifestados na conduta; e pelos mecanismos atribucionais de enfrentamento, no manejo da ansiedade e do estresse perante situações adversas, como um mercado de trabalho competitivo, por exemplo (BANDURA, 1987, 1989, 1992, 2007; BLOSTEIN, 1989). Bzuneck (1996) traz um exemplo quanto à matemática para ilustrar a 
diferença entre auto-eficácia e autoconceito, referindo que um aluno pode revelar autoconceito positivo em relação a essa área de conhecimento, mas frente a um problema novo, poderá julgar-se sem condições de resolvê-lo, isto é, não terá crença de auto-eficácia no grau desejado. Desta forma, o autor defende a ideia de que a crença de auto-eficácia restringe-se, a cada caso, a uma tarefa bem específica com que a pessoa se defronta (ingressar no mercado de trabalho, por exemplo), enquanto que o autoconceito, mesmo quando se refere a áreas específicas (como no exemplo citado), ainda tem um caráter mais genérico do que auto-eficácia. Bandura (2007) acredita que as crenças de auto-eficácia funcionam como determinantes das ações, em vez de simples reflexos secundários delas. Desta forma, afeta o desenvolvimento vocacional na medida em que predispõe o indivíduo a interessar-se por atividades profissionais nas quais ele se percebe competente, além de estar associada ao bom desempenho profissional (LENT; BROWN; HACKETT, 1996). Para Bandura (1992), pessoas com baixos escores de auto- eficácia podem desenvolver comportamentos de evitação, devido às expectativas negativas sobre seu futuro desempenho. Por outro lado, sujeitos que acreditam em seu sucesso profissional tendem a assumir uma postura mais ativa no que diz respeito ao direcionamento de suas carreiras.

Deste modo, universitários com crenças de auto-eficácia positivas podem comprometer-se de maneira mais ativa com seu futuro profissional, através de comportamentos exploratórios vocacionais, ainda durante o período da graduação. Estes comportamentos tratam-se de ações presentes na preparação individual para escolha de uma carreira e seu objetivo é obter informações sobre o sujeito da ação e sobre os contextos de interesse, a fim de orientar as ações futuras (TEIXEIRA; GOMES, 2005). Para Super (1963a), o comportamento exploratório tem o intuito de solucionar problemas através da reunião de informações sobre o próprio sujeito e sobre o meio, sendo que esta busca de informação envolve experimentação, investigação, tentativas, testes de hipóteses, entre outros comportamentos. $\mathrm{O}$ autor acredita que esta conduta normalmente é constante na vida do sujeito e tende a aumentar em períodos que antecedem e seguem etapas de mudança.

Em um estudo longitudinal realizado com estudantes universitários (GÖKS; LASSANCE, 1995, 1997) foram identificadas as diferentes etapas na relação do aluno com a Universidade e o curso. Os autores salientam que no momento do ingresso o jovem está envolto por sentimentos de entusiasmo e vitória (por ter passado no vestibular). Um segundo momento seria marcado pelas decepções com a instituição de ensino, professores e preocupações em relação à escolha profissional. No terceiro momento há um interesse maior pela continuidade 
do curso e envolvimento em atividades acadêmicas reforça a satisfação com a escolha. O último momento caracteriza-se pela proximidade com o fim do curso, onde a avaliação da formação contribuirá para as expectativas quanto à atuação profissional. Este último momento torna-se propício a um aumento na atividade exploratória, pois ela proporciona uma maior decisão de carreira, auto-eficácia vocacional além do desenvolvimento de expectativas realistas em relação à inserção no mercado de trabalho (BARDAGI, 2007; SPARTA; BARDAGI; ANDRADE, 2005; TEIXEIRA, 2002; TEIXEIRA, BARDAGI; HUTZ, 2007). Em uma pesquisa realizada com jovens em conclusão de curso, Teixeira e Gomes (2004) concluíram que o envolvimento dos estudantes em sua formação, especialmente em atividades práticas (estágios) não obrigatórias reforçam o senso de competência (auto-eficacia). Além disso, a participação em atividades acadêmicas (monitorias, estágios extracurriculares) e a identificação com a profissão são consideradas comportamentos exploratórios fundamentais para a elaboração de projetos realistas acerca da futura atuação na profissão escolhida. (BARDAGI, LASSANCE; PARADISO, 2003)

É comum que na idade adulta existam momentos de indecisão em relação à escolha profissional, pois o desenvolvimento profissional ocorre ao longo do ciclo vital (Savickas 1997), mas estar comprometido com a escolha em termos vocacionais promove uma avaliação mais otimista em relação às possibilidades, relativiza as dificuldades eventuais para obtenção de resultados e promove crenças de auto-eficácia positivas (BARDAGI, 2007; BARDAGI et. al, 2003, PAGOTTI; MENDONÇA; ALVES, 2006; SCHLEICH; POLYDORO; SANTOS, 2006). Uma pesquisa realizada com formandos de vários cursos na Universidade Federal do Rio Grande do Sul no ano de 1999 apontou que cerca de 54\% dos alunos percebiam dificuldades para se inserirem no mercado de trabalho após a formatura. Ainda, o comportamento de evadir (abandonar o curso superior) foi apontado por Bardagi (2007) como resultado de uma fragilidade na escolha inicial, pouca atividade exploratória, e expectativas irrealistas sobre a carreira.

Teixeira e Gomes (2004) em seu estudo qualitativo com orientação fenomenológica, concluíram que formandos dos cursos de Farmácia e Odontologia que tinham projetos profissionais realistas apresentavam crenças na qualificação e capacitação profissional. Em outra pesquisa com formandos de diversas áreas estes mesmos autores constataram que a percepção de oportunidades, clareza de autoconceito e auto-eficácia profissional foram as variáveis que mais contribuíram para a predição da decisão de carreira (TEIXEIRA; GOMES, 2005). De uma forma unânime estes estudos comprovam a necessidade de implementar 
atividades relacionadas ao desenvolvimento de metas profissionais realistas para que os estudantes lidem de modo efetivo com a transição para o mercado de trabalho.

O presente estudo propõe-se a avaliar as variáveis autoconceito, auto-eficácia e comportamento exploratório e outras variáveis contextuais e pessoais (sexo, idade, curso, etc) e estabelecer relações entre elas a fim de demonstrar sua influência no processo de transição universidade-mercado de trabalho. Dessa forma, pretende contribuir com os estudos sobre desenvolvimento vocacional de universitários e auxiliar com informações que possam servir para elaboração de estratégias de intervenção para os estudantes em final de curso.

\section{MÉTODO}

Participantes: Participaram deste estudo 231 estudantes formandos de 17 cursos diferentes da Universidade de Caxias do Sul. Os participantes, homens e mulheres (74,5\%) com idades entre 18 e 30 anos $(\mathrm{M}=23,2$; $\mathrm{DP}=2,76)$, estavam cursando o último ano de sua primeira graduação. A área de Humanas concentrou 26\% dos participantes, a área de Exatas 28,1\%, a área de Saúde/ Biológicas 30,3\% e a área de Letras e Artes 15,6\%. O quadro1 apresenta outras características sócio-demográficas dos alunos.

\begin{tabular}{|l|c|c|}
\hline & Frequência & Percentual \\
\hline Sexo & & $25,5 \%$ \\
\hline Feminino & 172 & $74,5 \%$ \\
\hline Masculino & 59 & $85,3 \%$ \\
\hline Estado Civil & 197 & $13 \%$ \\
\hline Solteiro & 30 & $1,3 \%$ \\
\hline Casado & 3 & $0,4 \%$ \\
\hline Separado & 1 & \\
\hline Viúvo & & $69,7 \%$ \\
\hline Reside com & 161 & $8,7 \%$ \\
\hline Pais & 20 & $5,6 \%$ \\
\hline Sozinho & 13 & $10,8 \%$ \\
\hline Amigos & 25 & $5,2 \%$ \\
\hline Família Própria & 12 & \\
\hline Outros & 31 & $13,4 \%$ \\
\hline Renda Familiar & 77 & $33,3 \%$ \\
\hline Até 1500 Reais & 50 & $21,6 \%$ \\
\hline De 1501 a 3000 Reais & 40 & $17,3 \%$ \\
\hline De 3001 a 4500 Reais & 33 & $14,4 \%$ \\
\hline De 4501 a 6000 Reais & & \\
\hline Acima de 6000 Reais & & \\
\hline
\end{tabular}

Quadro 1. Características sócio-demográficas dos alunos. 
Instrumentos: Para coleta de dados, foram utilizados os seguintes instrumentos:

a) Questionário Sócio-Demográfico e Vocacional: especialmente desenvolvido para caracterizar a amostra e obter dados a respeito da trajetória acadêmica e satisfação com a escolha profissional;

b) Escalas de autoconceito e auto-eficácia profissional (TEIXEIRA, 2002): o instrumento compõe-se de sete itens para avaliação da autoeficácia e 10 questões referentes ao autoconceito. É uma escala Likert de cinco pontos indicando diferentes níveis de concordância com as afirmações;

c) Escala de Exploração Vocacional para Universitários - EEV (TEIXEIRA; BARDAGI; HUTZ, 2007): instrumento desenvolvido para avaliar as duas dimensões principais do comportamento exploratório vocacional (exploração de si mesmo e exploração do ambiente), composto por 24 itens cujas respostas são distribuídas em uma escala Likert de cinco pontos.

Procedimentos e Considerações éticas: Inicialmente foi solicitada autorização da Universidade, através do Contato com Pró-Reitoria de Graduação. Após o aceite, foram feitos contatos com as coordenações dos cursos a fim de esclarecer os objetivos do estudo e solicitar coleta de dados. Para coleta dos dados, os participantes responderam aos instrumentos em aplicações realizadas coletivamente em sala de aula. Cada sessão de aplicação foi precedida de uma breve explicação dos objetivos do estudo e durou aproximadamente 20 minutos. A participação no estudo foi voluntária, tendo sido solicitado aos participantes a assinatura do Termo de Consentimento Livre e Esclarecido, construído a partir das orientações do Conselho Nacional de Saúde (Resolução 196/1996) e do Conselho Federal de Psicologia (Resolução 016/2000) acerca da ética na pesquisa com seres humanos. Durante a coleta e análise dos dados foram tomadas medidas necessárias para garantir o anonimato e a confidencialidade dos mesmos. O projeto foi aprovado pelo Comitê de Ética em pesquisa do Instituto de Psicologia da UFRGS (Protocolo 2008072).

\section{RESULTADOS}

Os alunos em sua maioria $(70,1 \%)$ possuem atividades remuneradas, sendo que a grande parte refere que a atividade que desempenha está ligada ao curso $(52,8 \%)$ em que estão se formando. Um número significativo de estudantes $(58,4 \%)$ nunca participou e atualmente não tem nenhuma atividade ligada ao 
curso como monitoria, bolsa de iniciação científica ou estágios extracurriculares. Dentre os que assinalaram participar de atividades (que não são excludentes), $32 \%$ realizam estágio, $6,1 \%$ têm bolsa de pesquisa e $13 \%$ fazem monitoria. Grande parte dos estudantes $(77,1 \%)$ referiu estar cursando a primeira graduação e a maioria (55\%) nunca prestou vestibular para outros cursos.

Em relação à satisfação com a escolha, $25,1 \%$ referem estar muito satisfeitos, $53,2 \%$ dizem estar satisfeitos, $18,2 \%$ pouco satisfeitos e $9 \%$ insatisfeitos. Quanto aos planos em relação ao futuro, para a maioria dos alunos o projeto inclui conseguir um emprego na área e profissão $(51,5 \%)$ e continuar os estudos (36,4\%). Um percentual significativo $(60,6 \%)$ acredita que não terá dificuldade para realizar o primeiro projeto. Apesar disso, o tempo médio estimado para a maioria dos estudantes $(43,8 \%)$ para a realização do primeiro projeto após a formatura é de mais de um ano chegando a 18 meses; $36,8 \%$ acreditam que levarão de três meses a um ano para a realização de seus planos; $21,2 \%$ dos estudantes acreditam que irão levar um tempo de 12 a 15 meses.

Testes de associação Qui-Quadrado apontaram que não houve associação entre sexo e participar de atividades no curso, ter planos futuros definidos, percepção de dificuldades para obtenção de metas ou nível de satisfação com a escolha profissional. Houve associação entre sexo e ter outra atividade remunerada, em que os homens, em maior frequência do que as mulheres têm outro trabalho fora do curso $\left(X^{2}=14,72 ; g l=1 ; p<0,01\right)$. Já em relação ao comportamento exploratório, testes $t$ de comparação de médias apontaram que as mulheres apresentaram níveis mais altos em exploração do ambiente e na exploração total, em comparação com os homens ( $t=-2,20$; $\mathrm{gl}=229$; $\mathrm{p}<0,05$; $\mathrm{t}=-2,26 ; \mathrm{gl}=229 ; \mathrm{p}<0,05$, respectivamente), não tendo havido diferenças em relação à exploração de si. Os testes de comparação de médias também não apontaram diferenças entre homens e mulheres nas medidas de auto-eficácia profissional e clareza de autoconceito.

Quando se avalia o impacto da área de formação, observou-se que não houve associação entre área e nível de satisfação com a escolha profissional ou ter planos definidos para após a graduação. Em relação a ter outro trabalho fora do curso, os alunos de Exatas com maior frequência possuem atividades remuneradas e os alunos de Letras/Artes não possuem $\left(X^{2}=36,73 ; g l=3 ; p<0,001\right)$. Em relação à percepção de dificuldades para obtenção de metas, os alunos de Saúde/Biológicas em maior frequência declararam perceber dificuldades e os alunos de Exatas declararam em maior frequência não perceber dificuldades para realização do projeto profissional $\left(X^{2}=11,35 ; \mathrm{gl}=3 ; \mathrm{p}<0,01\right)$. Quanto à participação em atividades no curso, os alunos de Humanas em maior frequência 
têm atividades e os alunos de Letras/Artes não têm atividades $\left(X^{2}=30,72 ; \mathrm{gl}=3\right.$; $\mathrm{p}<0,001)$. Análises de variância indicaram que não há diferenças nos níveis de exploração de si ou exploração do ambiente, nem nos níveis de clareza de autoconceito e auto-eficácia profissional nos alunos das quatro áreas.

Os alunos que têm atividade remunerada fora do curso (trabalham) declararam, com maior frequência do que os que não trabalham, não perceber dificuldades para a obtenção de metas profissionais $\left(\mathrm{X}^{2}=7,72 ; \mathrm{gl}=1 ; \mathrm{p}<0,05\right)$. Em relação a ter planos definidos para após a graduação, nível de satisfação com a escolha ou participar de atividades no curso, não houve diferenças entre alunos que têm ou não trabalho remunerado fora do curso. Análises de variância mostraram que houve diferença nos níveis de auto-eficácia profissional e de exploração do ambiente entre os alunos que têm ou não planos definidos para após a graduação $[\mathrm{F}(2,266)=7,16 ; \mathrm{p}<0,01 ; \mathrm{F}(2,266)=5,06 ; \mathrm{p}<0,01$; respectivamente] os alunos que não sabem o que vão fazer ao concluir o curso apresentaram níveis significativamente menores de exploração do ambiente e também de auto-eficácia do que os alunos que estão em dúvida sobre o que fazer; em relação à auto-eficácia, também os alunos que já têm planos definidos apresentaram níveis maiores nesta medida do que os alunos que estão em dúvida. Ao analisarmos os níveis de satisfação com a escolha, os alunos muito satisfeitos apresentaram maior exploração do ambiente do que os demais $[\mathrm{F}(3$, $265)=4,68 ; p<0,01]$ não havendo diferenças para as medidas de exploração de si, clareza de autoconceito e auto-eficácia profissional.

O quadro 2 apresenta as médias gerais e também os índices de consistência interna (Alpha de Cronbach) das escalas de exploração, auto-eficácia profissional e clareza de autoconceito para a amostra total. Houve grande variação entre os índices de clareza de autoconceito e exploração vocacional. Percebe-se, ainda, que todos os instrumentos apresentaram boa confiabilidade.

\begin{tabular}{|l|c|c|c|c|r|}
\hline Escalas & $\begin{array}{l}\text { Pontuação } \\
\text { Máxima }\end{array}$ & $\begin{array}{l}\text { Pontuação } \\
\text { Mínima }\end{array}$ & $\begin{array}{l}\text { Consistência Interna } \\
\text { (Alpha de Cronbach) }\end{array}$ & Média & $\begin{array}{r}\text { Desvio } \\
\text { Padrão }\end{array}$ \\
\hline Auto-eficácia & 30 & 10 & 0,827 & 24,54 & 4,40 \\
\hline $\begin{array}{l}\text { Clareza de } \\
\text { auto-conceito }\end{array}$ & 50 & 15 & 0,838 & 40,24 & 7,06 \\
\hline $\begin{array}{l}\text { Exploração } \\
\text { vocacional }\end{array}$ & 120 & 42 & 0,902 & 84,43 & 14,39 \\
\hline $\begin{array}{l}\text { Exploração do } \\
\text { ambiente }\end{array}$ & 70 & 21 & 0,883 & 48,58 & 9,65 \\
\hline $\begin{array}{l}\text { Exploração } \\
\text { de si }\end{array}$ & 50 & 18 & 0,854 & 35,85 & 7,01 \\
\hline
\end{tabular}

Quadro 2. Índices de Confiabilidade, Pontuações Mínima e Máxima, Médias e Desvios- Padrão das Escalas. 
O Quadro 3 apresenta as correlações encontradas entre estas e outras variáveis avaliadas. Uma análise de regressão mostrou que as variáveis clareza de autoconceito, exploração do ambiente e idade formaram o modelo que explicou $30 \%$ da variância da auto-eficácia profissional.

\begin{tabular}{|l|c|c|c|c|c|c|}
\hline & $(1)$ & $(2)$ & $(3)$ & \multicolumn{1}{c|}{$(4)$} & \multicolumn{1}{c|}{$(5)$} & $(6)$ \\
\hline Idade & - & 0,18 & $-0,03$ & $-0,15$ & 0,10 & 0,02 \\
\hline Auto-eficácia & 0,18 & - & 0,40 & 0,00 & $-0,00$ & 0,33 \\
\hline Clareza de auto-conceito & $-0,03$ & 0,40 & - & $-0,07$ & 0,07 & 0,17 \\
\hline Exploração vocacional & $-0,02$ & 0,33 & 0,17 & - & $-0,00$ & - \\
\hline Exploração do ambiente & 0,00 & 0,38 & 0,23 & 0,04 & - & 0,90 \\
\hline Exploração de si & $-0,05$ & 0,15 & 0,03 & 0,07 & $-0,03$ & - \\
\hline
\end{tabular}

Quadro 3. Correlações entre as variáveis vocacionais

(valores acima de 0.10; $p<0.01$ ).

\section{DISCUSSÃO}

Este trabalho teve por objetivo avaliar as trajetórias acadêmicas, satisfação com curso e expectativas profissionais de alunos formandos de diferentes áreas, além de relacionar estes aspectos com clareza de autoconceito, auto-eficácia profissional e comportamento exploratório. Inicialmente, o perfil sócio-demográfico e vocacional da amostra revela o retrato típico do estudante universitário, jovem, em sua maioria solteiro, que reside com os pais, com renda familiar média, confirmando dados já apontados pela literatura desta área (BARDAGI, 2007; TEIXEIRA, 2002). Apesar disso, há características heterogêneas que podem ser evidenciadas por estarem ligadas à localidade e instituição onde foram coletados os dados. Embora os respondentes em sua maioria fossem do sexo feminino, a maior parte dos estudantes pertence à área de ciências exatas, uma área normalmente preferida pelos homens. (SCHULENBERG; GOLDSTEIN; VONDRACEK, 1991)

Isto pode ter relação com o fato de a universidade onde foi realizado o estudo situar-se no segundo pólo metal-mecânico do país, onde a maior oferta de emprego está ligada à área industrial. Nesse sentido, a maioria dos alunos possui atividades remuneradas, o que em uma universidade privada poderia ser um dado esperado já que muitos universitários custeiam seus próprios estudos. Entretanto, a maior parte dos que exercem estas atividades revelam que o trabalho tem ligação com seu curso, o que não costuma ser comum em outros levantamentos e pode também ter relação com o contexto específico de trabalho na região. 
O comportamento exploratório tem por objetivo reunir certas informações sobre o próprio sujeito ou sobre o meio a fim de verificar ou encontrar subsídios que auxiliem o indivíduo a escolher, preparar, assumir, ajustar-se ou progredir em uma ocupação ou carreira (JORDAN, 1963). Atitudes como a realização de estágios extracurriculares, participação em bolsas de pesquisa, monitorias são esperadas dos graduandos em fase final (SPARTA; BARDAGI; ANDRADE, 2005) de curso. Por outro lado, um número significativo de alunos nunca participou e nem participa de atividades acadêmicas ligadas ao curso $(58,4 \%)$. Dentre os que participam, os estágios extracurriculares foram indicados como a atividade mais frequente, o que confirma um foco voltado à busca por uma atividade remunerada. A pouca atividade exploratória durante a graduação e o comprometimento com um emprego antes mesmo da conclusão do curso, nos leva a pensar em um perfil de um estudante-trabalhador, diferente daquele já apontado por pesquisas feitas em universidades públicas (TEIXEIRA, 2002; BARDAGI, 2007). Entretanto, Rabello (1973) já publicara estudos revelando uma tendência de jovens universitários a estarem inseridos no mercado de trabalho. As conclusões da autora correlacionaram este fato com a condição sócio-econômica dos jovens. O estudo em questão complementa os pressupostos de Rabello (1973) no que se refere ao sexo e atividade remunerada. Dentre os participantes, os homens em maior frequência do que as mulheres revelaram ter uma atividade remunerada, o que demonstra coerência com as questões culturais em relação ao trabalho. Todavia, as mulheres apresentam níveis mais altos de exploração do ambiente.

Uma maior participação em atividades acadêmicas como monitorias e bolsas de pesquisa poderia contribuir para que os estudantes tivessem contato com uma outra face profissional após a formatura, ou seja, a carreira acadêmica. No entanto, é necessário que as universidades estimulem o estudante a engajar-se nestas atividades o que abre espaço para que novos estudos surjam envolvendo esta problemática. Ademais, em relação ao questionamento sobre a relação do trabalho com a área, esta questão foi avaliada de forma quantitativa; talvez estudos qualitativos possam permitir uma outra visão do que seria estar exercendo uma função relacionada à futura profissão ou não, segundo a perspectiva do próprio estudante.

A participação em atividades acadêmicas, bem como o comportamento exploratório, pode aumentar ou diminuir significativamente o compromisso com a escolha (BARDAGI, 2007; BROOKS; CORNELIUS; GREENFIELD; JOSEPH, 1997; LASSANCE, 1997). Este estudo comprovou um número relevante de estudantes satisfeitos com sua opção pelo curso $(78,3 \%)$ o que pode 
ser reflexo do perfil de aluno comentado anteriormente. Porém esta variável apontou correlação negativa em relação à área de formação, embora os alunos das exatas tenham oportunidades de trabalho formal com maior frequência em relação aos de outras áreas em função das características do mercado de trabalho e das especificidades da região. Ainda, são os alunos das Humanas que participam com mais frequência de atividades acadêmicas em detrimento dos estudantes de Artes/Letras. Os cursos avaliados no primeiro grupo incluem: jornalismo, psicologia, relações públicas entre outros, cursos que contêm um currículo que viabiliza o contato com a prática antes mesmo do último ano. Já a área de Letras/Artes, na qual foram pesquisados cursos como arquitetura e artes plásticas, a baixa participação nas atividades extracurriculares pode ter relação com a própria sistemática da área. Estes dados apontam para a necessidade das universidades estimularem seus alunos a ter contato com a prática, através de programas de incentivo e projetos de pesquisa.

Apesar disso, é unânime o projeto de conseguir um emprego na profissão para a qual estão se graduando após a conclusão do curso. Como segundo plano, os jovens elencaram continuar os estudos. Além disso, 60,6\% dos universitários acreditam que não terão dificuldades para realização do primeiro projeto. Esta também foi a conclusão de outras pesquisas (GODIN, 1997, TEIXEIRA, 2002, TEIXEIRA; GOMES, 2004, RUEDA; MATINS; CAMPOS, 2004) envolvendo esta temática. O empenho pessoal e financeiro que demanda um curso superior (no caso da universidade ser privada) pode ser visto como um investimento passível de retorno futuro, mesmo para aquelas áreas nas quais o mercado aponta uma escassez de oportunidade, tendo em vista que a correlação entre os planos para depois da formatura e área de atuação foi negativa. Em relação a isto, Teixeira (2002) conclui em sua tese de doutorado que o otimismo em demasia ao final de uma graduação pode ser entendido como um mecanismo protetivo utilizado pelo sujeito, uma mola propulsora para levar adiante a concretização dos ideais em questão.

Os alunos das ciências Exatas têm um otimismo maior em relação ao das áreas Biológicas e da Saúde tendo em vista o já comentado aquecido mercado de trabalho para área de exatas da região. Este otimismo aparece também em relação ao tempo que eles imaginam conseguir realizar estes planos, já que o tempo médio estimado pelos estudantes (de todas as áreas) é de um ano a 18 meses. Nos dias atuais, o tempo esperado para que um profissional se estabeleça no mercado de trabalho pode ser de até três anos, pois a competitividade tem aumentado em função do próprio acréscimo de profissionais graduados. Além disso, o mercado de trabalho tem se tornado mais exigente, pois com a diminui- 
ção de seu quadro de pessoal, as empresas têm exigido que as pessoas tenham mais capacidade de aprender e de se adaptar à nova realidade. Desta forma, a educação formal passa a ser uma dentre outras competências (polivalência, dinamismo, habilidade social, etc) que o sujeito deve ter para atender esta demanda. (RUEDA et al., 2004).

Estes fatores associados a um desconhecimento dos formandos do perfil esperado pelo mercado de trabalho podem contribuir com a construção de expectativas irrealistas geradoras de frustrações diante da realidade de sua profissão (RUEDA; COLS., 2004). Em um estudo qualitativo, Teixeira e Gomes (2004) constataram que aqueles estudantes que já conheciam a realidade através de um comportamento exploratório mantido durante a graduação não mudaram suas expectativas no último ano de curso. Entretanto, os estudantes cuja formação deteve-se no currículo do curso ao chegarem próximos à formatura, demonstraram expectativas mais pessimistas. Um estudo qualitativo com a amostra desta pesquisa poderia investigar se o otimismo dos jovens em conseguir um trabalho está conectado com projetos profissionais imediatos e realistas (como elaborar um currículo, onde buscar trabalho).

Dentre os alunos que não sabem o que vão fazer após a formatura encontraram-se níveis significativamente menores de exploração do ambiente do que aqueles que já têm projetos definidos. O comprometimento com a formação para além do currículo pode contribuir para que o jovem desenvolva preferências dentro de sua área, além de favorecer o auto-conceito vocacional. Este último está ligado à avaliação pessoal que o sujeito faz de suas aptidões, escolhas e valores e isto só se torna claro para o indivíduo quando ele oportuniza a si próprio experimentar, testar hipóteses, elaborar conclusões (SUPER, 1963b).

Uma característica heterogênea como a clareza de auto-conceito tornase determinante para o estabelecimento do que Super (1963b) chamou de maturidade vocacional. Este conceito traduz a capacidade do indivíduo para enfrentar as tarefas do desenvolvimento com as quais ele é confrontado como consequências do seu desenvolvimento social e biológico, de uma parte, e das necessidades da sociedade em relação às outras pessoas que alcançam este estado de desenvolvimento, de outra parte. Desta maneira, espera-se que a maturidade vocacional seja estabelecida no período de conclusão de curso, pois durante a graduação o jovem já fez uma escolha inicial quando passou no vestibular, além das oportunidades de contato que teve com a sua e outras áreas. Entretanto, esta questão abre possibilidades para um estudo longitudinal, no qual a variável clareza de auto-conceito vocacional poderia ser mensurada em diferentes etapas da graduação a fim de se ter uma medida do quanto o fa- 
tor tempo (tendo em vista um avanço no currículo do curso) e comportamento exploratório podem nortear esta clareza.

A auto-eficácia, por sua vez, compreende o julgamento das pessoas sobre sua capacidade de executar determinada tarefa (BANDURA, 1992), e, para aqueles participantes que estenderam suas atividades acadêmicas para extracurriculares, os níveis de auto-eficácia foram maiores. É interessante assinalar a correlação positiva entre a clareza de autoconceito e auto-eficácia, comprovando os pressupostos teóricos que afirmam que quanto mais o sujeito se conhece no papel que desempenha, mais ele depositará em si a confiança necessária para enfrentar situações aversivas, ou processos de mudança (TEIXEIRA, 2002; TEIXEIRA; GOMES, 2004; BARDAGI 2007; BARDAGI et al., 2003)

Os alunos que já têm planos definidos para o futuro também apresentam índices maiores de auto-eficácia demonstrando comprometimento com a profissão, o que os fortalece para lidar com as peculiaridades do mercado de trabalho além de assumirem uma maior responsabilidade com sua inserção. Vale ressaltar que estas variáveis têm íntima relação com a clareza de auto-conceito, formando a tríade comportamento exploratório de si e do ambiente, influenciando diretamente na clareza que o sujeito tem sobre si mesmo e no quanto ele acredita ser capaz de obter sucesso no desempenho de determinada atividade.

Este estudo pôde comprovar a correlação existente entre as variáveis estudadas, além de chamar a atenção para a relevância das universidades incentivarem, através de diferentes programas, o comprometimento do jovem com sua formação. No entanto, os problemas que envolvem esta temática não se esgotam nesta pesquisa, o que abre possibilidade para novas problemáticas. Ainda são poucos os estudos envolvendo a orientação profissional como um processo de maturação durante a graduação. Desta forma, abrem-se precedentes envolvendo esta mesma temática com um número maior de cursos, um equilíbrio de gênero e até mesmo sua extensão para outras regiões através de um estudo de segmento. No entanto, pode-se concluir pela necessidade de um acompanhamento dos jovens concluintes a fim de que seu processo de transição ocorra de forma satisfatória prevenindo inclusive futuras patologias derivadas de expectativas frustradas pela realidade de cada profissão.

\section{REFERÊNCIAS}

BANDURA, Albert. Pensamiento y acción: fundamentos sociales. Barcelona: Martinez Rocca, 1987. 
BANDURA, Albert. Human agency in social cognitive theory. American Psychologist, Arlington, EUA, v. 44, n. 9, p. 1175-1184, 1989.

BANDURA, Albert. Exercise of personal agency thought the selféfficay mechanism. In: SCHWARZER (Org.) Selff-efficacy: thought control of action Washington. Hemisphere: 1992, p. 3-38.

BANDURA, Albert. O exercício da agência humana pela eficácia coletiva. In: BANDURA, Albert; AZZI, Roberta; POLYDORO, Soely (Orgs). Teoria social cognitiviva: Conceitos Básicos. Porto Alegre: Artes Médicas, 2007. p. 115-121.

BARDAGI, Marúcia Patta. Evasão e comportamento vocacional de universitários: Estudos sobre o desenvolvimento de carreira na graduação. 2007. 230 p. Tese (Doutorado) - Universidade Federal do Rio Grande do Sul, Porto Alegre, 2007.

BARDAGI, Marúcia Patta; LASSANCE, Maria Célia; PARADISO, Angela. Trajetória acadêmica e Satisfação com a Escolha Profissional de Universitários em Meio de Curso. Revista Brasileira de Orientação Vocacional, São Paulo, SP, v 4, n. 1-2, p. 153-166,2003.

BLOSTEIN, David. The role of goal instability and career self=efficacy in the career exploration process. Journal of Vocational Behavior, n 35, p. 194-203, Oct, 1989. [on line]. Disponível na Base de Dados CAPES: Science Direct,

BROOKS, Linda; COMELIUS, Allen; GREENFIELD, Ellen; JOSEPH, Robin. The relation of career-related work or internship experiences to the career development of college seniors. Journal of Vocational Behavior, $\mathrm{n}$ 46, p. 332-349, May 1995. [on line]. Disponível na Base de Dados CAPES: Science Direct,

BZUNECK, José Aloysio. Crenças de auto-eficácia em professores do primeiro grau e sua relação com outras variáveis de predição e de contexto. Arquivos Brasileiros de Psicologia, Rio de Janeiro, v. 48, n. 4, p. 57-89, 1996.

CAMPBELL, James D.; TRAPNELL, Paul D.; HAINE, S. J. ; KATZ, Ira M. ; LAVALLE, Loraine. F. ; LEHMAN, Darrin R. Self-concept clarity: Measurement, personality correlates, and cultural boundaries. Journal of Personality and Social Psycology, [n.70, p. 141-156,1996. [on line]. Disponível na Base de Dados CAPES: Science Direct. 
CONSELHO FEDERAL DE PSICOLOGIA. Resolução para pesquisa com seres humanos. Resolução 016/2000. Brasília, DF, 2000.

GÖKS, A; LASSANCE, Maria Célia. A formação da identidade profissional em estudantes universitários - pensando a prática profissional [Abstracts]. In: SALÃO DA INICIAÇÃO CIENTÍFICA DA UFRGS, 7., 1995, Porto Alegre. Anais do... Porto Alegre: UFRGS, 1995. p. 255.

GÖKS, A; LASSANCE, Maria Célia. A formação da identidade profissional em estudantes universitários - As trajetórias acadêmicas[Abstracts]. In: SALÃO DA INICIAÇÃO CIENTÍFICA DA UFRGS, 9., 1997, Porto Alegre. Anais do ... Porto Alegre: UFRGS, 1997. p. 369.

GODIM, Sonia Maria G. Perfil profissional e mercado de trabalho: relação com formação acadêmica pela perspectiva de estudantes universitários.

Estudos de Psicologia, Natal, v.2, n. 7, p. 299-309, jul, 1997.

JORDAN, Jason P. Exploratory behavior: The formation of self and occupational conceps. In:. SUPER, D.; STARISHEVSKY, R.; MATLIN, N.; JORDAAN, J.P. (Eds). Career development: Self-concept theory: Essays in vocational development. p. 42-48. New York: College Entrance Examination Board, 1963.

LENT, Robert William.; BROWN, Steve. D.; HACKETT, Gail. Career development from a social cognitive perspective. En: BROWN, D.; BROOKS, L. (Orgs.). Career choice and development. 3. ed. San Francisco: Jossey-Bass, 1996. p.373-421.

PAGOTTI, Antônio. Wilson; MENDONÇA, Daniela Maria R.; ALVES, Mara Aparecida. As preocupações dos estudantes universitários do curso de psicologia de duas instituições de ensino superior, 2006. $<$ Disponível em www.psicologia.pt.br. > Acesso em: 15 de dez. 2008.

RUEDA, Fabián Javier M.; MARTINS, Luciana; Julio; CAMPOS, Keli Cristina L. Empregabilidade: o que os universitários entendem sobre isso? Psicologia: Teoria e Prática, São Paulo, SP, v. 6, n. 2, p. 63-73, 2004.

RABELLO, O. Universidade e trabalho: perspectivas. Campinas: Unicamp/Instituto Nacional de Estudos e Pesquisas Educacionais, 1973.

SAVICKAS, Mark. L. Career Adaptability: an integrative construct for lifespan, life-space theory. The Career Development Quartely, Broken Arron, USA, v. 45, p. 247-259, 1997. 
SCHELEICH, Ana Lúcia R.; POLYDORO, Soely Aparecida; SANTOS, Acácia Aparecida A. Escala de satisfação com a experiência acadêmica de estudantes do ensino superior. Avaliação Psicológica, Itatiba, SP, v. 5, n. 1, p. 11-20, junho 2006.

SCHULENBERG, Jonh ; GOLDSTEIN, Avery E. ; VONDRACEK, Fred W. Gender differences in adolescents' career interests: Beyond main effects. Journal of Research on Adolescence, v. 1, p. 37-61, 1991. [on line]. Disponível na Base de Dados CAPES: Science Direct SPARTA, Mônica; BARDAGI, Marúcia Patta; ANDRADE Ana Maria J. Exploração vocacional e informação profissional percebida em estudantes carentes. Aletheia, Canoas, RS n. 22, p. 79-88, dez, 2005.

SUPER, Donald E. Self-concepts in vocational development. In: SUPER Donald et al. (Orgs.). Career development: Self concept theory. New York: College Entrance Examination Board - Columbia University, 1963a. p. 1-14. SUPER, Donald E. Self. Toward making self-concept theory operational In: SUPER Donald E. et al. (Orgs.). Career development: self concept theory. New York: College Entrance Examination Board - Columbia University, 1963b. p. 1-14.

TEIXEIRA, Marco Antonio Pereira. A experiência de transição entre a universidade e o mercado de trabalho na adultez jovem. 2002.210p.Tese (Doutorado) - Universidade Federal do Rio Grande do Sul, Porto Alegre, 2002.

TEIXEIRA, Marco Antonio Pereira; GOMES, William Barbosa. Estou me formando... e agora? Reflexões e perspectivas de jovens formando universitários. Revista Brasileira de Orientação Profissional, São Paulo, SP, v.5, n. 1, p. 47-52, 2004.

TEIXEIRA, Marco Antonio Pereira; GOMES, Wiliam Barbosa. Decisão de Carreira entre Estudantes em Fim de Curso Universitário. Psicologia: Teoria e Pesquisa, São Paulo, SP, v. 21, n. 3, p. 327-334, 2005.

TEIXEIRA, Marco Antonio Pereira, BARDAGI, Marúcia Patta; HULTZ, Cláudio Simon. Escalas de Exploração Vocacional (EVV) para Universitários. Psicologia em Estudo, Maringá, v. 12, n. 1, p. 195-202, 2007.

UFRGS. Pró-reitoria de Ensino. Pró-reitoria Adjunta de Graduação. Perfil e representações dos estudantes de graduação da UFRGS: Relatório final. Porto Alegre: UFRGS, 2003. 